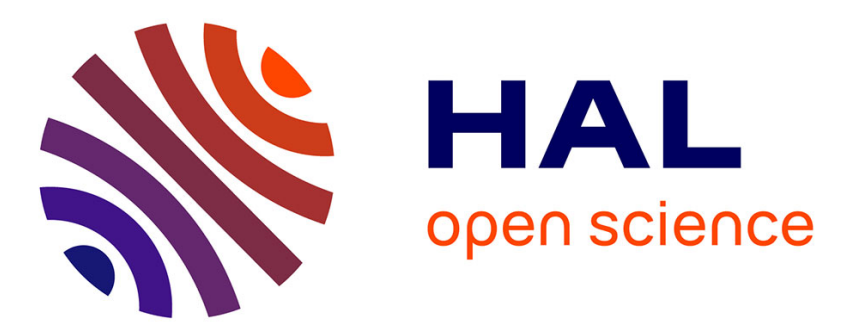

\title{
A wearable haptic ring for the control of extra robotic fingers
}

\author{
Irfan Hussain, Giovanni Spagnoletti, Claudio Pacchierotti, Domenico \\ Prattichizzo
}

\section{> To cite this version:}

Irfan Hussain, Giovanni Spagnoletti, Claudio Pacchierotti, Domenico Prattichizzo. A wearable haptic ring for the control of extra robotic fingers. AsiaHaptics 2016, Dec 2016, Kashiwanoha, Japan. pp.323325, 10.1007/978-981-10-4157-0_55 . hal-01935247

\section{HAL Id: hal-01935247 \\ https://hal.inria.fr/hal-01935247}

Submitted on 26 Nov 2018

HAL is a multi-disciplinary open access archive for the deposit and dissemination of scientific research documents, whether they are published or not. The documents may come from teaching and research institutions in France or abroad, or from public or private research centers.
L'archive ouverte pluridisciplinaire HAL, est destinée au dépôt et à la diffusion de documents scientifiques de niveau recherche, publiés ou non, émanant des établissements d'enseignement et de recherche français ou étrangers, des laboratoires publics ou privés. 


\title{
A wearable haptic ring for the control of extra robotic fingers
}

\author{
Irfan Hussain, Giovanni Spagnoletti, Claudio Pacchierotti, and Domenico \\ Prattichizzo
}

Dept. of Information Engineering and Mathematics, University of Siena, Siena, Italy. Dept. of Advanced Robotics, Istituto Italiano di Tecnologia, Genova, Italy.

\begin{abstract}
This paper present a wearable haptic ring called "hRing" to control the soft extra robotic finger and to render haptic informations to provide cutaneous stimuli. The "hRing" is a novel wearable cutaneous device for the proximal finger phalanx. The soft extra robotic is finger designed to be used by chronic stroke patients to compensate for the missing hand function of their paretic limb.

The hRing consists of two servo motors, a vibro motor, two pairs of push button and a belt. The servo motors move the belt placed in contact with the user's finger skin. When the motors spin in opposite directions, the belt presses into the user's finger, while when the motors spin in the same direction, the belt applies a shear force to the skin.

The soft finger is an underactuated modular robotic finger worn on the paretic forearm by means of an elastic band. The device and the paretic hand/arm act like the two parts of a gripper working together to hold an object. It has been designed to be wearable,

Two chronic stroke patients took part to our experimental evaluation on how the proposed integrated robotic system can be used for hand grasping compensation.

The hRing enabled the patients to easily control the motion of the robotic finger while being provided them with haptic feedback about the status of the grasping action. The patients found the system useful for ADL tasks, the hRing easy to use, and the haptic feedback very informative.
\end{abstract}

\section{Overview of the system}

We propose a novel wearable cutaneous device for the proximal finger phalanx, called "hRing". It consists of two servo motors, a vibrotactile motor, two pairs of push buttons, and a belt. The servo motors move the belt in contact with the user's finger skin. When the motors spin in opposite directions, the belt presses into the user's finger, while when the motors spin in the same direction, the belt applies a shear force to the skin. The device structure is symmetrical and each side features two push buttons, enabling the hRing to be used both on the left and right hand. A preliminary version of this wearable device has been presented in [1]. With respect to the version proposed in [1], the new hRing presented in this work offers enhanced mobility of the finger phalanx, ambidexterity, a vibrotactile motor, and a lighter body structure.

In this work, we use the hRing as an interface to interact with a novel underactuated soft robotic finger (SRF), presented in [2] (see Fig. 1). The proposed SRF 
is an extra robotic finger to be worn on the forearm by means of an elastic band. The robotic device has been devised for compensating hand function in chronic stroke patients to re-gain the grasping capabilities of their paretic hand. Preliminary results with chronic stroke patients has been proposed in [3]. The robotic finger and the paretic hand act like the two parts of a gripper, working together to hold an object. The proposed finger device consists of two main parts: a flexible finger and a support base. The flexible finger has a modular structure. The SRF has a single actuator that can flex/extend the whole finger through a tendon. It houses the actuator, and an elastic band allows the user to secure the device at the forearm. Similarly to the hRing, the structure of the base is symmetrical, enabling the robotic finger to be worn both on the left and right arm. A FSR force sensor is placed at the tip of the robotic finger.

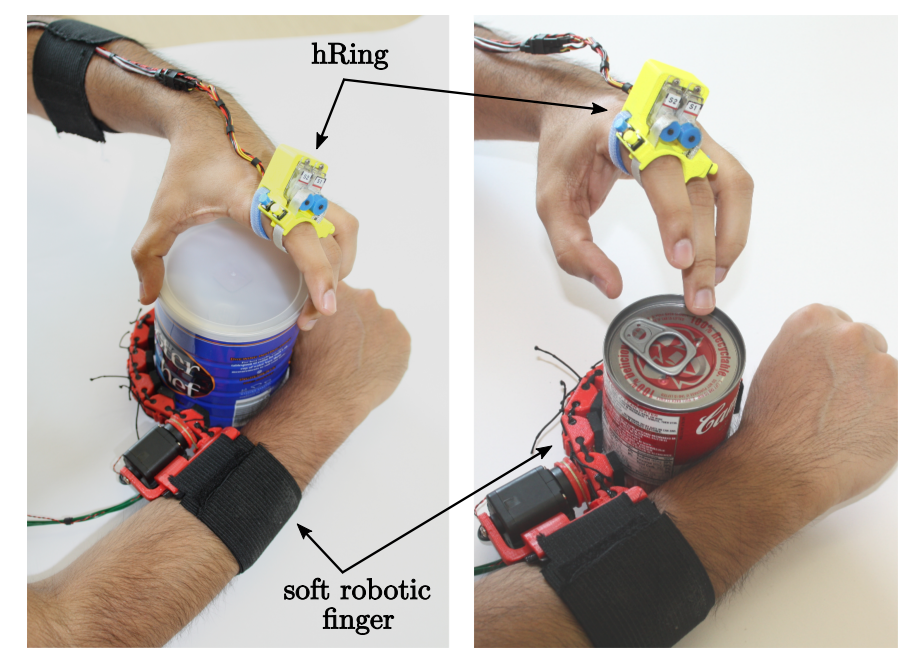

Fig. 1. The integrated system used by a patient in Activities of Daily Living (ADL).

\section{Methods and Experiments}

Two chronic stroke patients took part to our experimental evaluation on how the proposed integrated robotic system can be used for hand grasping compensation. The subjects were required to wear the robotic finger on their paretic hand and the hRing on the healthy hand index finger (see Fig. 1). The proposed compensatory tool can be used by subjects showing a residual mobility of the arm. Each patient uses the SRF for bimanual tasks typical in Activities of Daily Living (ADL), such as unscrewing a cap of tomato jar, opening a popcorn bag, or opening a can of beans. The hRing interface is used to both control the flexion/extension motion of the robotic finger and to provide the patient with haptic feedback about the forces exerted by the robotic finger on the environment.

The patient can press the blue button on the external side of the hRing with the thumb of the same hand to initiates the flexing procedure of the robotic finger. 
The finger will close until a contact with an object through the FSR mounted on its fingertip is detected. As soon as the contact happens, the robotic finger stops its flexion and the hRing generates a short vibration burst to notify the patient. If the patient presses the blue button again, the finger increases the grasping force on the object. During this process, the hRing belt squeezes the patient's finger proportionally to the grasp force applied by the robotic finger on the environment. When the patient is satisfied with the grasping configuration, he or she can proceed with the task. Finally, pressing the yellow button on the hRing will initiate the opening procedure of the robotic finger. The hRing releases its belt and provides a vibration burst when the opening procedure is completed.

\section{References}

1. C. Pacchierotti, G. Salvietti, I. Hussain, L. Meli, and D. Prattichizzo, "The hRing: a wearable haptic device to avoid occlusions in hand tracking," in Proc. IEEE Haptics Symposium (HAPTICS), 2016.

2. I. Hussan, G. Salvietti, G. Spagnoletti, and D. Prattichizzo, "The soft-sixthfinger: a wearable emg controlled robotic extra-finger for grasp compensation in chronic stroke patients," IEEE Robotics and Automation Letters, 2016.

3. I. Hussain, G. Salvietti, L. Meli, C. Pacchierotti, and D. Prattichizzo, "Using the robotic sixth finger and vibrotactile feedback for grasp compensation in chronic stroke patients," in Proc. IEEE/RAS-EMBS International Conference on Rehabilitation Robotics (ICORR), 2015. 